\title{
Daily activity patterns of Saanen goats in the semi-arid northeast of Brazil
}

\author{
Jória Leilane de Albuquerque Paulo, Fívia de Araújo Lopes ${ }^{1}$
}

\footnotetext{
${ }^{1}$ Programa de Pós-graduação em Psicobiologia, Departamento de Fisiologia, Universidade Federal do Rio Grande do Norte, Natal, RN, Brasil.
}

\begin{abstract}
The objective of the study was to characterize the daily feeding activity patterns of Saanen goats (Capra hircus) as a function of changes in climatic variables. The investigation was conducted in the municipality of Cruzeta, $300 \mathrm{~km}$ from the city of Natal, Brazil. Seventeen free-ranging female Saanen goats were selected for observation, wherein they were kept on a pasture with native vegetation and also received concentrated feed in a trough. Observational records of behavior on pasture were collected using focal animal and scan sampling for these specific behaviors: ruminating while standing or lying down, standing idly or lying down, walking, grazing and eating. Eating was the predominant activity observed. The frequency of some behaviors changed in accordance with certain climatic variables, with behaviors that require more active movement occurring in the morning hours, when temperatures are milder, exhibiting higher frequencies. These observations indicate that animals adjust their daily activities in order to minimize the effects of the stress caused primarily by environmental conditions.
\end{abstract}

Key Words: applied ethology, behavior, bioclimatology

\section{Introduction}

Goat farming in Northeastern Brazil, mostly conducted by small-scale farmers, is associated with a number of objectives that are linked to satisfying short-term economic needs, basic security and survival. The Saanen goat (Capra hircus) provides a variety of resources that can be crucial to alleviating poverty, encouraging greater interaction and cooperation among people and providing more stability to family units (França et al., 2006).

The Saanen goat breed was first introduced to Brazil for this very purpose and has proved highly efficient in combating poverty. According to reports by Capritec (2011), the breed is widely used because of its excellent milk production. Thus, research that relates daily activity patterns in social and feeding behavior to levels of milk production is innovative and highly relevant to increasing both milking and breeding objectives, as such data can be utilized in offering strategic comforts to minimize the animal stress.

Investigating and understanding goat behavior is important in that it enables changes to be made in inappropriate management practices, with the goal of mitigating negative effects of stress and maximizing animal welfare, thereby influencing the animals into producing

Received December 23, 2013 and accepted July 3, 2014.

Corresponding author: jorialeilane@yahoo.com.br

http://dx.doi.org/10.1590/S1516-35982014000900002

Copyright (@) 2014 Sociedade Brasileira de Zootecnia. This is an Open Access article distributed under the terms of the Creative Commons Attribution Non-Commercial License, which permits unrestricted non-commercial use, distribution, and reproduction in any medium, provided the original work is properly cited. better and higher yields. Among the behaviors observed to examine such an issue in this context, eating may be used to evaluate animal responses to a specific environment, pasture or other manageable situation and is an important instrument for successful production in animal farming. Factors involved in regulating food and water consumption can also be important to making modifications that improve production (Mendonça et al., 2004).

Saanen goats are classified as exotic animals in Brazil and are almost always bred in confinement because they require a more targeted feed management than some other breeds. This sort of captive context reflects a common aspect of study design in applied ethology research, where it must be assumed that the behavioral characterization of such animals may not necessarily represent their natural behavior. Moreover, goats are naturally gregarious and social animals that exist in organized hierarchies where particular animals are dominant, subordinate or leaders (Alados \& Escos, 1992), a group-living situation that is not always compatible with animal farm production.

Studying social and feeding behaviors of Saanen goats enables the characterization of a large part of their daily activity patterns, favoring a more direct understanding of the interactions between them and an assessment of how these factors may influence individual feeding behavior. The objective of acquiring such information is to promote and inform the implementation of more adequate management practices, especially in terms of improving animal welfare and, consequently, production to potentially alleviate more poverty and suffering. 
In light of this objective, it is also important to consider that most small-scale farmers in northeastern Brazil do not have the resources to invest in modifying, let alone providing proper facilities, and must put animals out to graze to a much greater degree. The scarcity of data regarding the feeding behavior of Saanen goats hinders a real understanding of its role in their daily activities. As such, the present study aimed to characterize and describe the feeding activity patterns of Saanen goats on native pastures of the semi-arid region of northeastern Brazil.

\section{Material and Methods}

The current study was conducted at the experimental station of the Rio Grande do Norte Agricultural Research Corporation (EMPARN), located in the municipality of Cruzeta, $220 \mathrm{~km}$ from the state capital of Rio Grande do Norte, Natal, in the extreme Northeast region of Brazil. The study area covers an area of $288 \mathrm{~km}^{2}$, located at $6^{\circ} 24^{\prime} 42^{\prime \prime} \mathrm{S}$ latitude, 36 $47^{\prime} 22^{\prime \prime} \mathrm{W}$ longitude at an altitude of $232 \mathrm{~m}$.

As the subjects of our study, we selected 17 pure-bred female Saanen goats (Capra hircus), eight of which were lactating. Age varied from one to seven years and weight from 23 to $68 \mathrm{~kg}$. At the beginning of the experiment, the animals were dewormed, various body measurements were taken and they were fitted with different colored collars to facilitate individual identification.

The observation study was carried out from May to June, 2011. The experiment was conducted over a period of seven weeks, on two consecutive days per week, 14 days of data collection. Total rainfall during this period was $4 \mathrm{~mm}$, relative humidity was $67 \%$ and the maximum and minimum temperatures were $30{ }^{\circ} \mathrm{C}$ and $22^{\circ} \mathrm{C}$, respectively.

In the early morning, lactating goats were taken to the milking parlor before being reunited with non-lactating individuals to receive concentrated feed. The animals were distributed to identical troughs, $2.80 \mathrm{~m}$ long $\times 25 \mathrm{~cm}$ wide and $23 \mathrm{~cm}$ high, each of which was placed into a $10 \mathrm{~m}$ wide and $12 \mathrm{~m}$ long enclosure. All of the animals were then released to graze on a native pasture measuring $2,881.5 \mathrm{~m}^{2}$, where they spent the rest of the day. In the late afternoon they were collected for trough-feeding again and then moved to the milking parlor for the second time that day. The goats spent the night in pens and were subjected to the same procedure the following day.

The goats were offered a balanced feed, in quantities based on $4 \%$ of their body weight, and containing $60 \%$ cornmeal, $20 \%$ soybean meal, $15.5 \%$ wheat bran, $1.5 \%$ urea, $2.0 \%$ of a mineral mixture and $1.0 \%$ limestone.
The behavioral categories were classified and defined as follows:

Feeding behavior: Grazing - searching for food (foraging activity), characterized by movement with the head bent towards the pasture; Eating - ingesting the food acquired during grazing; Ruminating while standing - in a standing position and ruminating simultaneously; Ruminating while lying down - in a lying down position and ruminating simultaneously.

Other behaviors: Walking - moving through the pasture by walking, with the head inclined forwards; Idle while standing - in a standing position and not ruminating; Idle while lying down - in a lying down position and not ruminating.

In the week prior to our data collection period, the subject animals underwent a period of adaption to the presence of observers to avoid unnecessary interference with their natural behavior. Observational data were gathered in accordance with the standardized farm management practices already in use, so as not to disrupt the normal routine of the animals. To collect data on animals on pasture, the area was monitored by two trained observers, recording all of the observed behaviors. Animal focal sampling, with instantaneous recording, was also used. The latter method was based on that described by Carvalho et al. (2007), which established an observation interval of up to twenty minutes. In the current study, we used a window of 10 minutes with the goal of maximizing uptake behavior, while the exact behavior was verified every $30 \mathrm{~s}$ during this interval. Observation periods were in the morning between $06.30 \mathrm{~h}$ and $12.00 \mathrm{~h}$ and between $13.00 \mathrm{~h}$ and $16.30 \mathrm{~h}$, for each animal in the group. The observation sequence for each individual in the study group was randomized, and all animal ethical norms were respected.

The Kolmogorov-Smirnov test was applied to assess the distribution of the data. Normality was not established, so nonparametric statistical tests were used for intergroup comparison. For comparisons between observation periods, in order to obtain a breakdown of activities, each activity (dependent variables) was evaluated as a function of the time period (morning and afternoon; independent variables) using the Mann-Whitney test. The Friedman test was applied to analyze activity frequencies (dependent variables) and compare activities within each time period. The Wilcoxon test was used to compare pairs of activities. For the 21 post-hoc tests, we applied the Bonferroni correction $(\mathrm{P}=0.05 / 21=0.00238)$ to each observation period. We also compared the frequency of each activity (dependent variable) from weeks 1 to 7 using the Kruskal-Wallis test, as well as pairs of weeks using the Games-Howell approach. 


\section{Results}

In general, when comparing behavioral activities between observation periods, only ruminating while standing $(\mathrm{U}=26,542.0 ; \mathrm{Z}=-2.19 ; \mathrm{P}=0.03)$ and grazing $(\mathrm{U}=12,456.5 ; \mathrm{Z}=-2.316 ; \mathrm{P}=0.021)$ showed a significant difference between observation shifts. The former behavior was more frequent in the afternoon, while the latter was more frequent in the morning. The remaining behavioral categories (idle while standing, idle while lying down, ruminating while lying down, walking, grazing and eating) showed no differences in their expression as a function of time of day $(\mathrm{U}>25,093.0 ; \mathrm{Z}>-1.95 ; \mathrm{P}>0.05)$ (Figure 1).

Although significant differences between the periods were observed only for ruminating while sanding and grazing, in general, animals performed activities involving movement throughout the morning hours, including walking and eating, which require greater energy expenditure and increase heat accumulation. In the afternoon, idle behavior while standing was more common than walking or ruminating

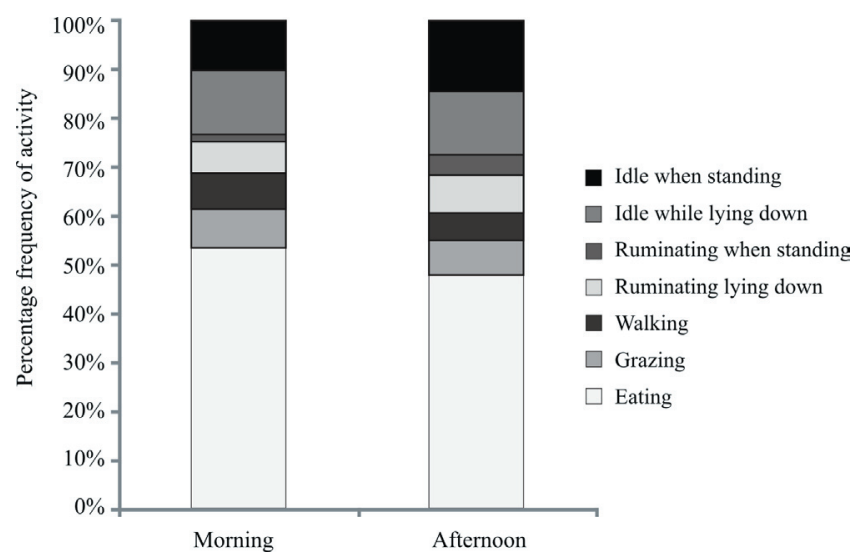

Figure 1 - Distribution of behavioral activities in the morning and afternoon for Saanen goats on native pasture.

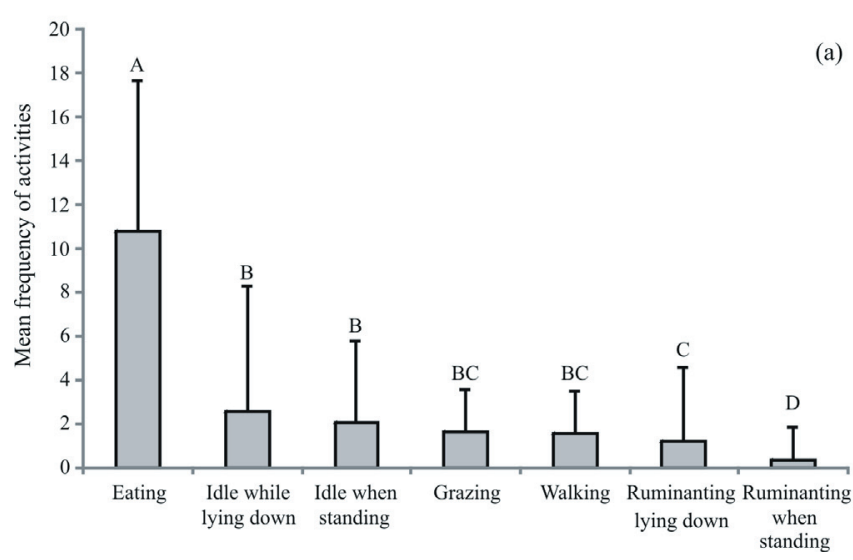

Different letters represent statistical differences between observed behaviors. while standing or lying down. More static behavior such as idleness and rumination occurred in the afternoon in order to maintain more efficient homeothermy.

Grazing and walking activities exhibited an interesting pattern, with a higher frequency of occurrence in the morning compared with rumination while standing $(\mathrm{P}<0.001)$ (Figure 2a). This pattern was inverted during the afternoon hours in relation to rumination while lying down (Figure 2b), reinforcing the natural eating habits of the goats, which are characterized by more grazing in the morning and rapid food ingestion.

Differences were also observed in the morning (Figure 2a) with regard to idle and ruminating behavior, wherein goats spent more of their time idle or ruminating while lying down than they did standing.

Since climate affected Saanen goat behavior to the point of altering their daily activity patterns, comparisons were made over the course of the study, given the frequent changes in weather, and allowing for a more detailed analysis of the effect of the environment on these animals. Nevertheless, not all behaviors exhibited significant variations. The results for mean frequencies of idleness while standing over the seven-week period of the experiment $(\mathrm{H}=37.43 ; \mathrm{gl}=6 ; \mathrm{P}<0.001)$ (Figure 3) show statistical differences $(\mathrm{P}=0.009)$ between weeks 1 and 6 , when idleness while standing was higher in the first week than in the sixth. Maximum temperature in the first week was $29.8^{\circ} \mathrm{C}$, with rainfall of $3.8 \mathrm{~mm}$ and relative humidity of $57 \%$.

For walking activity $(\mathrm{H}=22.39 ; \mathrm{gl}=6 ; \mathrm{P}=0.001)$ as a function of time in weeks, significant frequencies were observed during the first week compared with the remaining weeks $(\mathrm{P}<0.024)$ (Figure 4). When beginning to graze in a certain area, the animals first conduct a visual assessment, establishing quantitative and qualitative references.

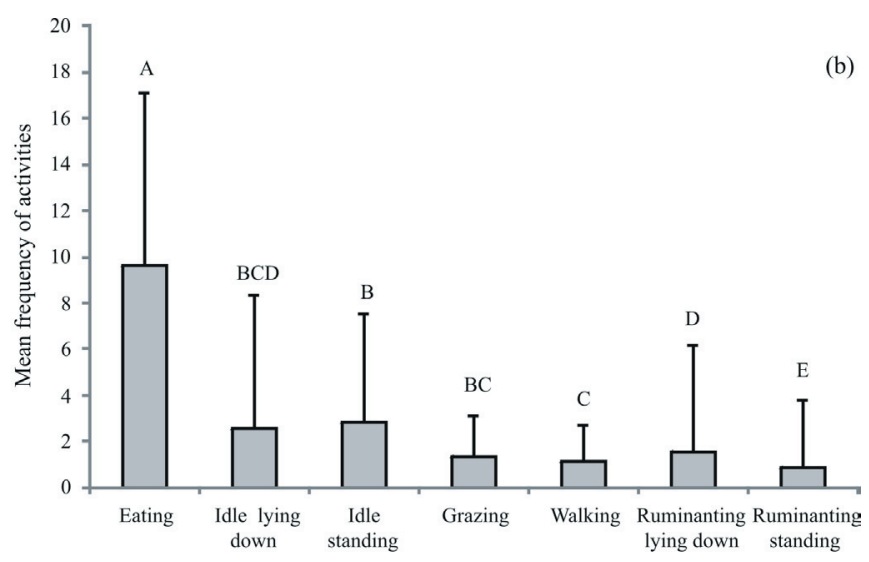

Figure 2 - Frequency of behavioral activities in the morning (a) and afternoon (b) for Saanen goats on native pasture. 
Eating behavior $(\mathrm{H}=22.59 ; \mathrm{gl}=6 ; \mathrm{P}=0.001)$ was more prevalent in weeks 3,5 and 6 when compared with week $2(\mathrm{P}<0.047)$. With respect to rumination while lying down $(\mathrm{H}=22.59 ; \mathrm{gl}=6 ; \mathrm{P}=0.001)$, week 3 showed greater frequency than weeks 3, 5, 6 and $7(\mathrm{P}<0.032)$ (Figure 5).

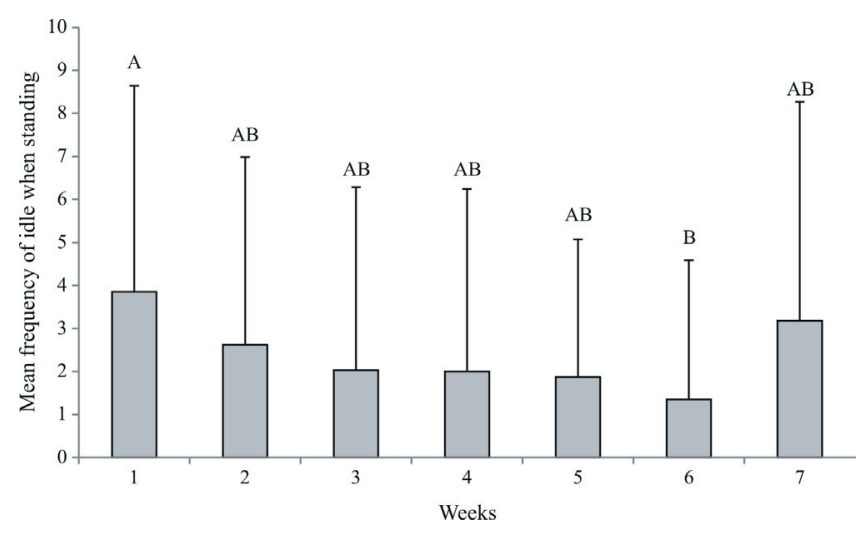

Different letters indicate significant differences (Kruskal-Wallis test).

Figure 3 - Mean frequency for idle activity while standing for Saanen goats on native pasture.

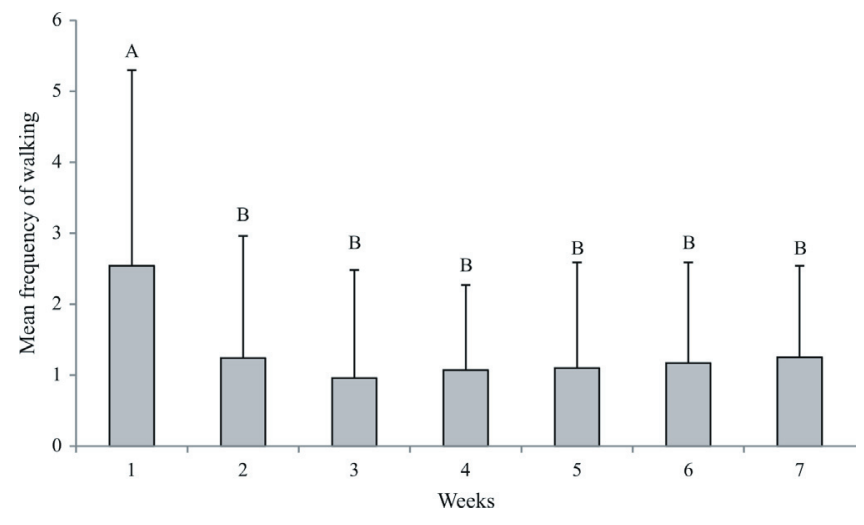

Different letters indicate significant differences (Kruskal-Wallis test).

Figure 4 - Mean frequency of walking activity among Saanen goats on native pasture.

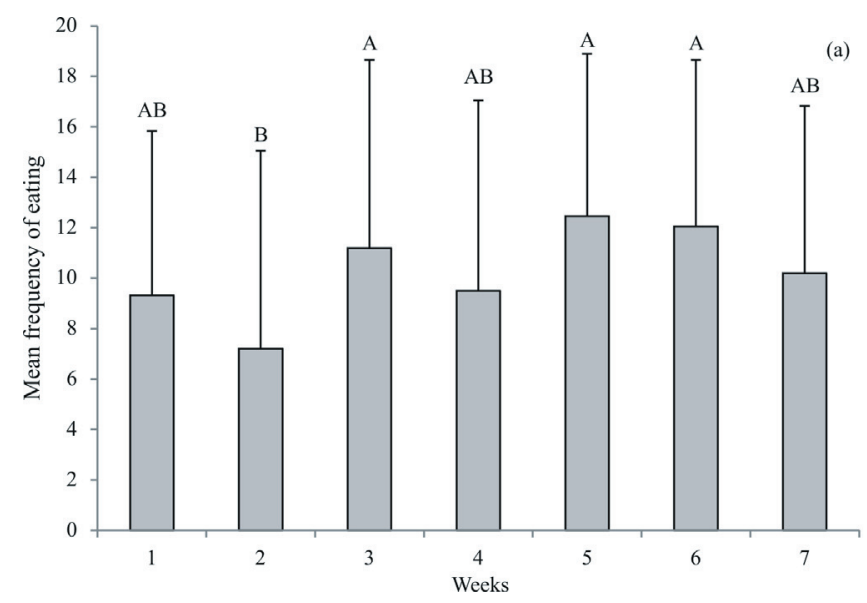

\section{Discussion}

Understanding the distribution of daily activities for farm animals can be an important tool by favoring the implementation of better routine management practices, especially for small-scale farmers. Is this work, we analyzed the activity patterns of female Saanen goats managed according to a milk production routine that included feed supply and grazing time on a native pasture in the semiarid region of Brazil. The distribution of daily activities was analyzed according to the time of day as well as over the duration of the study period in weeks, and considering some changes in climate.

Goats reduce their frequency of physical effort when placed in an environment that requires greater energy expenditure. The distribution of daily behaviors was directly related to climate variables. In our study area, the animals experienced higher ambient temperatures (approximately $30.5^{\circ} \mathrm{C}$ ) and more intense sunshine in the afternoon. This caused the animals to reduce their levels of activity during this period to remain within a comfort zone, thereby minimizing endogenous heat accumulation and maintaining physiological patterns within the normal range. According to Baêta (2010), the optimal conditions for goats are temperatures between 20 and $30{ }^{\circ} \mathrm{C}$ and humidity levels above $50 \%$.

The differences recorded between observation periods for the rumination while standing and grazing behaviors may be related to temperatures at the study site. As such, the animals remained standing to reduce surface contact with the ground and minimize conductive heat transmission in the afternoon hours, while looking for food at higher frequencies in the morning hours when temperatures are coolest (Ribeiro, 1997). This reduces direct sun exposure and endogenous heat storage, maintaining thermal comfort levels and ensuring that their physiological parameters

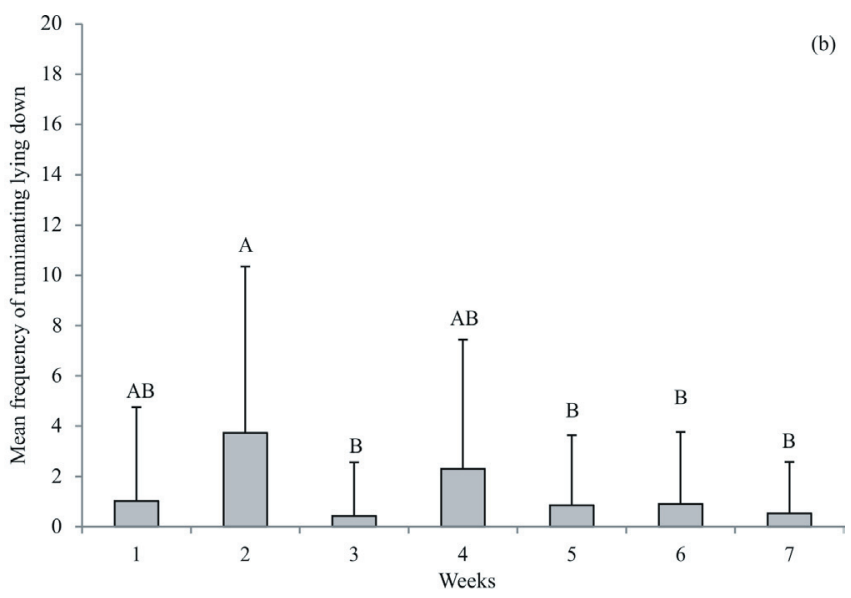

Different letters indicate significant differences (Kruskal-Wallis test).

Figure 5 - Mean frequency for eating (a) and ruminating when lying down (b) among Saanen goats on native pasture. 
remain normal. We also observed a decline in walking activity during the afternoon hours, presumably in order to minimize the accumulation of endogenous heat. This also reinforces the idea that idleness while standing dissipates heat, saves energy and prevents the additional accumulation of heat through direct contact with the ground.

In accordance with our results, Aich et al. (2007) found that goats increased their grazing time during the winter and decreased their time spent walking, indicating a shift in their food-searching strategy and behavior to reduce energy expenditure. During the summer, these authors also recorded a higher frequency of idle time, which suggests that a thermally uncomfortable environment induces such animals to less movement and subsequent heat buildup. Sharma et al. (1998) also reported that Indian goat breeds showed different diurnal behavior patterns, spending more time grazing during the rainy season $(504.9 \mathrm{~min})$ than in winter (376.5 $\mathrm{min})$ or summer (266.9 $\mathrm{min})$.

When we compared the behaviors in each period, eating activity was also more frequently observed than other behaviors during the afternoon hours. Despite being subjected to higher degrees of sun exposure, the animals still prioritized eating, allowing us to conclude that they spend most of the day engaged in this activity. Sufficient eating ensures the individual animal survival and welfare, improves its productive performance and generates betterquality products that have more value for the consumer and generate greater profits for the producer.

Standing can be characterized as a behavior that requires more energy than lying down; however, in the case of the animals observed here, standing diminishes the transmission of heat through direct contact with the ground and tends to decrease heat stress. Furthermore, once they are satiated and their nutritional demands are satisfied, the observed lack of activity afterwards, as opposed to displaying behaviors that require movement, such as walking and grazing, suggests that the animals must remain idle to save energy.

Furtado (2008) describes increased idleness after $10.00 \mathrm{~h}$, precisely when temperatures begin to rise. On the other hand, the results of Barros et al. (2007) contrast with those from the present study. These authors observed higher incidences of idleness while standing than lying down, but suggested that this behavior allows the goats to sharpen their sense of sight and smell, which facilitates their search for food and water. Despite the validity of this argument, we believe the pattern observed in our study is more closely related to the climate differences between regions, which appear to have a direct influence on goat behavior with regard to standing or lying down behavior with respect to the time of day.
Given that the animals in the present study were put out to graze during the day and received only a small supplement in the form of concentrated feed, we expected less idleness and higher levels of rumination overall. This prediction was based on our observation that the pasture contains a substantial amount of fiber, which stimulates rumination and lowers idle behavior. However, our results contrasted with these expectations as idle periods were observed to be more common than rumination behavior. This may indicate behavioral differences in pasture and stable environments, and represent a behavioral divergence related to the extreme climatic conditions of the study areas. Rumination is a demanding metabolic activity that produces heat. Thus, as an alternative means of reducing heat production, ruminants prioritize this activity for periods of greater thermal comfort, such as late afternoon or at night. Damasceno et al. (1999) studied Friesian cows in the city of Brasília (Brazil) and found higher rumination rates in late afternoon hours and at night. The authors argued that this is due to lower air temperatures, suggesting that the heat produced by rumination is more tolerable during periods of cooler temperatures. Furlan et al. (2006) and Ruckebusch and Bueno (1978) also showed that the pattern of expression for this activity presents a greater frequency at night.

Goats are selective foraging animals by nature and therefore tend to spend a significant amount of time walking and grazing in search of the most nutritious forage (Parente et al., 2005). The observations of the current study occurred during the short period of high rainfall for the semiarid region, which is otherwise characterized by high temperatures and very little rain.

Average rainfall during the months of data collection was $4.1 \mathrm{~mm}$ and there was abundant pasture during the study period. As such, the animals did not need to walk for significant periods in order to find food, which led to higher incidences of eating behavior, notably greater than the levels of other activities over both shifts.

Based on the data collected here, we conclude that the environment in the first week can be considered less stressful than the remainder of the study period. On the other hand, the sixth week is critical in terms of understanding these data because relative humidity was lower and air temperature was higher, creating a more thermally uncomfortable environment (Silva, 2000). We expected contrasting behavior, with predominantly idle behavior being observed in a thermally uncomfortable setting since, to maintain homeothermy, the animals should engage in more stationary behavior. A possible explanation is that the animals may be adjusting their basic physiological functions, such as respiratory rate (Srikandakumar et al., 2003) and 
heart rate (Lyons \& Price, 1987; Morh et al., 2002), even in environments that are outside of their thermal comfort zone, in an attempt to maintain a stable internal temperature.

Another possible explanation is associated with the nutritional concept, which involves understanding the costs and benefits of expressing a certain behavior. By spending less time standing and idle, while increasing their feeding activity, the animals can remain well-nourished, since they tend to lose energy under stressful conditions such as maintaining homeothermy under extreme climatic conditions. Research conducted by Barreto (2008) on supplementation levels in the diet of confined native goats found that animals fed low-concentrate diets reduced their idle activity and increased feeding behavior, in accordance with the energy balance of the diet. Barros et al. (2007) recorded similar results, with goats exhibiting greater feeding-related activity (around 71\%) than idleness (35\%) throughout the day. Even in situations of thermal discomfort, the animal prioritized feeding, ensuring a better nutritional status and thereby guaranteeing their survival.

We also observed that the goats walked more during the first week to assimilate the pasture area, which was extended in the beginning of the study period due to the relocation of males to another area. Walking behavior was subsequently reduced over the duration of the study, as the animals moved more directly to locations that offered better foraging and abandoning a certain patch where the ingestion rate at the site equaled the average rate of ingestion for the remainder of the entire area. Such a behavior pattern in herbivores is predicted by the Marginal Value Theorem (Charnov, 1976, cited by O'Reagain \& Schwartz, 1995).

In week 2 , the goats displayed a much higher rumination peak in comparison with other weeks; therefore, they may have eaten more during that week due to greater rumination during this same period. According to environmental data provided by the EMPARN meteorological station, low rainfall and high temperatures were recorded during the two weeks leading up to week 2, with $3.8 \mathrm{~mm}$ and $29^{\circ} \mathrm{C}$ in the second week and $0.9 \mathrm{~mm}$ and $31.4{ }^{\circ} \mathrm{C}$ in the first week. These data allow for a better understanding of the high rumination rates observed at that time, given that the fiber levels in the pasture may have increased in week 2 because of the low rainfall and elevated temperatures during the previous two weeks. This would make the pasture less nutritious and more fibrous, leading to longer rumination times. Pasture characteristics can alter the time spent ruminating, with higher fiber content resulting in a slower passage rate and increased rumination (Van Soest, 1994). A study conducted by Barreto (2008) recorded greater rumination activity in goats subjected to high-fiber diets.
The highest rainfall over the study period $(11.6 \mathrm{~mm})$ was recorded in week 3 . This may have caused animals to reduce rumination while lying in comparison with week 2 , which experienced an average rainfall of $4.3 \mathrm{~mm}$. When lying down, goats come into direct contact with the wet ground and eating activity may have been compensated by rumination during this week. It is important to emphasize that goats do not typically remain in wet areas since these sites carry a greater risk of infection by ectoparasites (Ribeiro, 1997).

\section{Conclusions}

In accordance with the environments into which they are placed, animals must make economic decisions to increase their chances of survival. The search for and acquisition of food are among the key activities for maintaining this survival. On the other hand, in the narrow margin between the costs and benefits of decision-making, goats modify the frequency of some behaviors according to climatic variables, exhibiting higher levels of behavior requiring movement in the morning, when temperatures are cooler. Thus, we can conclude that, as an exotic species to the semiarid-region of northeastern Brazil, Saanen goats have adjusted their activities in response to local climate conditions.

\section{Acknowledgments}

We would like to thank Universidade Federal do Rio Grande do Norte (UFRN) and the Coordination of Improvement of Higher Education Personnel (CAPES) for financial support and Agricultural Research Corporation (EMPARN) for the use of space for research development.

\section{References}

Aich, A. E.; Assouli, N. E.; Fathi, A.; Morand-Fehr, P. and Bourbouze, A. 2007. Ingestive behavior of goats grazing in the Southwestern Argan (Argania spinosa) forest of Morocco. Small Ruminant Research 70:248-256.

Alados, C. L. and Escos, I. 1992. The determinants of social status and the effect of female rank on productive success in dama and cuvier's gazelles. Ethology, Ecology \& Evolution 1:151-164.

Baêta, F. C. and Souza, C. F. 2010. Ambiência em edificações rurais conforto animal. 2.ed. UFV, Viçosa, MG.

Barreto, L. M. G. 2008. Comportamento ingestivo e utilização de nutrientes por caprinos Moxotó e Canindé submetidos a dietas com dois níveis de energia. Dissertação (M.Sc.). Universidade Federal da Paraíba, Areia.

Barros, C. S.; Dittrich, J. R.; Rocha, C.; Silva, C. J. A.; Rocha, F. M. P.; Monteiro, A. L. G.; Bratti, L. F. S. and Silva, A. L. P. 2007. Comportamento de caprinos em pastos de Brachiaria hibrida 
cv. Mulato. Revista da Faculdade de Zootecnia, Veterinária e Agronomia 14:187-206.

CAPRITEC, 2011. Soluções em caprinocultura e ovinocultura. Available at: $<$ http://www.capritec.com.br/csa/Rebanho/Saanen/RebSaa.htm>. Accessed on: Nov. 14, 2011.

Carvalho, G. G. P.; Pires, A. J. V.; Silva, H. G. O.; Veloso, C. M. and Silva, R. R. 2007. Aspectos metodológicos do comportamento ingestivo de cabras lactantes alimentadas com farelo de cacau e torta de dendê. Revista Brasileira de Zootecnia 36:103-110.

Damasceno, J. C.; Baccari Júnior, F. and Targa, L. A. 1999. Respostas comportamentais de vacas holandesas, com acesso à sombra constante ou limitada. Pesquisa Agropecuária Brasileira 34:709-715.

França, F. M. C.; Holanda Júnior, E. V. and Sousa Neto, J. M. 2006. Modelo de exploração de ovinos e caprinos para agricultores familiares do semi árido por meio do sistema agrossilvipastoril. Available at: $<$ http://www.caprilvirtual.com.br/Artigos/modelo_exploracao_ agrosilvipastoril_ov_cap.pdf $>$. Accessed on: Jul. 11, 2012.

Furlan, R. L.; Macari, M. and Faria Filho, D. E. 2006. Anatomia e fisiologia do trato gastrintestinal. p.1-23. In: Nutrição de ruminantes. Berchielli, T. T.; Pires, A. V. and Oliveira, S. G., eds. Funep, Jaboticabal.

Furtado, G. 2008. Respostas comportamentais de cabras Saanen submetidas a estresse térmico na Mesoregião Central Potiguar. Departamento de Aprendizagem Rural, SENAR - Serviço Nacional de Aprendizagem Rural, Natal, RN, Brasil.

Lyons, D. M. and Price, E. O. 1987. Relationships between heart rates and behavior of goats in encounters with people. Applied Animal Behavior Science 18:363-369.

Mendonça, S. S.; Campos, J. M. S.; Valadares Filho, S. C.; Valadares, R. F. D.; Soares, C. A.; Lana, R. P.; Queiroz, A. C.; Assis, A. J. and Pereira, M. L. A. 2004. Comportamento ingestivo de vacas leiteiras alimentadas com dietas à base de cana-de-açúcar ou silagem de milho. Revista Brasileira de Zootecnia 33:723-728.

Mohr, E., Langbein J. and Nürnberg G. 2002. Heart rate variability: a noninvasive approach to measure stress in calves and cows. Physiology \& Behavior 75:251-259.

O'Reagain, P. J. and Schwartz, J. 1995. Dietary selection and foraging strategies of animals on rangeland. Coping with spatial and temporal variability. p.419-424. In: International Symposium on the Nutrition of Herbivores. Clermont-Ferrand, France.

Parente, H. N.; Santos, E. M.; Zanine, A. M.; Oliveira, J. O. and Ferreira, D. J. 2005. Hábito de pastejo de caprinos da raça Saanen em pastagem de Tifton 85 (Cynodon ssp). Revista da Faculdade de Zootecnia, Veterinária e Agronomia 12:143-155.

Ribeiro, S. D. A. 1997. Caprinocultura: criação racional de caprinos. Editora Nobel, São Paulo.

Ruckebusch, Y. and Bueno, L. 1978. An analysis of ingestive behaviour and activity of cattle under field conditions. Applied Animal Ethology 4:301-313.

Silva, R. G. 2000. Introdução à bioclimatologia animal. Editora Nobel, São Paulo.

Sharma, K.; Saini, A. L.; Singh, N. and Ogra, J. L. 1998. Seasonal variations in grazing behaviour and forage nutrient utilization by goats on a semi-arid reconstituted silvipasture. Small Ruminant Research 27:47-54.

Srikandakumar, A.; Johnson, E. H. and Mahgoub, O. 2003. Effect of heat stress on respiratory rate, rectal temperature and blood chemistry in Omani and Australian Merino sheep. Small Ruminant Research 49:193-198.

Van Soest, P. J. 1994. Nutritional ecology of the ruminant. 2nd ed. Cornell University Press, Ithaca. 